\title{
Evaluation of Effectiveness of Information Booklet Regarding Self-Care among Patients Receiving Chemotherapy in Selected Hospitals of Wardha and Nagpur, India
}

\author{
Mahima Dipak Panbude ${ }^{1}$, Mayuri Manikrao Paropate², Mansi Vinod Pande 3 , \\ Priyanka Dayaram $\mathrm{Pal}^{4}$, Chatur Kamlakar Patil ${ }^{5}$, Ranjana Premnath Sharma ${ }^{6}$
}

\begin{abstract}
1, 2,3,4,5 Smt. Radhikabai Meghe Memorial College of Nursing, Datta Meghe Institute of Medical Sciences, (Deemed to Be University), Sawangi (M), Wardha, Maharashtra, India. ${ }^{6}$ Department of Medical Surgical Nursing, Smt. Radhikabai Meghe Memorial College of Nursing, Datta Meghe Institute of Medical Sciences, (Deemed to Be University), Sawangi (M), Wardha, Maharashtra, India.
\end{abstract}

\section{ABSTRACT}

\section{BACKGROUND}

The incidence rate for cancer reflects the number of new cases occurring in a specific population during a year, expressed as the number of cancer diagnosis per 10,000 people. Cancer is globally a major cause of death and morbidity and is currently witnessing an exponential increase in the number of malignancies. The present study was conducted to assess the knowledge regarding self-care among patients receiving chemotherapy, to evaluate the effectiveness of information booklet regarding selfcare among patients receiving chemotherapy and to find out the association between knowledge score regarding self-care among patients receiving chemotherapy in selected hospitals.

\section{METHODS}

An experimental study was undertaken on 60 purposively selected patients receiving chemotherapy in selected hospitals of Wardha and Nagpur district. One group pretest post-test research design was used in the study. Data was collected by using structured questionnaire during the month of December 2019. The duration of study was for 5 months from October 2019 to February 2020.

\section{RESULTS}

The findings of the study show that $33.33 \%$ patients had average knowledge score, $61.67 \%$ patients had good knowledge score and $5 \%$ patients had very good knowledge score in pre-test. Minimum knowledge score was 8 in pre-test and maximum knowledge score was 23 in pre-test. Mean knowledge score in pre-test was $15.53 \pm 2.98$ and mean percentage of knowledge score in pre-test was $44.38 \pm 8.52$. $11.67 \%$ of patients had good knowledge score, $81.67 \%$ of patients had very good knowledge score and $6.67 \%$ of patients had excellent knowledge score in post-test. Minimum knowledge score was 20 in post-test and maximum knowledge score was 30 in the post-test. Mean knowledge score in pre-test was $24.61 \pm 2.53$ and mean percentage of knowledge score in post-test was $70.33 \pm 7.25$. It indicates that information booklet is effective in improving knowledge of patients receiving chemotherapy.

\section{CONCLUSIONS}

Patients receiving chemotherapy have average knowledge regarding chemotherapy self-care. After providing information booklet, there was a very significant increase in the knowledge. The combined ' $t$ ' test was assessed in all hospitals for value of pretest knowledge and post-test knowledge score. Thus, it is concluded that the booklet on chemotherapy self-care is effective in improving the knowledge of patients receiving chemotherapy.

\section{KEY WORDS}

Cancer, Chemotherapy, Effectiveness, Self-Care
Corresponding Author: Ms. Mahima Dipak Panbude, Smt. Radhikabai Meghe Memorial College of Nursing, Datta Meghe Institute of Medical Sciences, (Deemed to Be University), Sawangi (M), War dha, Maharashtra, India.

E-mail: mahimapanbude245@gmail.com

DOI: $10.14260 /$ jemds/2021/280

How to Cite This Article:

Panbude MD, ParopateMM, Pande MV, et al. Evaluation of effectiveness of information booklet regarding self-care among patients receiving chemotherapy in selected hospitals of Wardha and Nagpur, India. J Evolution Med Dent Sci 2021;10(18):13291333, DOI: $10.14260 /$ jemds/2021/280

Submission 15-12-2020,

Peer Review 06-03-2021,

Acceptance 12-03-2021,

Published 03-05-2021.

Copyright (C) 2021 Mahima Dipak Panbude et al. This is an open access article distributed under Creative Commons Attribution License [Attribution 4.0 International (CC BY 4.0)] 


\section{BACKGROUND}

Cancer is the major cause of death worldwide. This problem is expected to rise universally, due to an aging population. Today, toxic habits such as smoking, unhealthy diet, sedentary lifestyle and reproductive changes have increased cancer risks. ${ }^{1}$ Chemotherapy is used as an important part of the multimodal approach to manage various malignancies. ${ }^{2}$

At present cancer is becoming one among the foremost current illness round the world. According to that, World Health Organization (WHO) estimates that the incidence of cancer will rise in following decades. In fact, this disease is estimated to be the second most common cause of death. Throughout the world, cancer ranks as the third important health problem. Unlike other illnesses, the treatment of cancer is for long duration and it is interspersed with complications and frequent admissions to hospital. Latest advancements in cancer care, especially in the development of novel chemotherapeutic and bio-therapeutic agents, have resulted in an increase of survival in cancer patients. Chemotherapeutic medications have been used in cancer therapy for several years. ${ }^{3}$

Cancer and its management present challenges to the health care system. More patients are undergoing chemotherapy in outpatient treatment centers than ever before because it is of least-cost and efficient for the patient. Patients have been treated with chemotherapy for hours in an outpatient clinic or doctor's office. Cancer patients undergoing chemotherapy need guidance on the medications they are taking and the self-care they need to take to help avoid severe complications. $^{4}$

Cytotoxic medications also known as chemotherapy drugs, antineoplastic, anticancer drugs contain a wide variety of chemical substances. They are widely used to treat cancer because of their ability to kill cancer cells by disrupting cell division. ${ }^{5}$ Chemotherapy is a procedure that uses therapeutic substances or drugs to kill cancer cells in the cell cycle process, or to use substances or medications to prevent cancer cell overgrowth and spreading. ${ }^{6}$

The main objective of treating the patient with chemotherapy is to maximize the death of tumour cells while sparing those normal cells with a high mitotic index to cure the client with cancer and control the growth when cure is not possible. ${ }^{7}$ Self-care is commonly used as a wider concept encompassing all measures taken by people to improve their own health and well-being, while self-management focuses more on the ability to handle day-to-day issues arising from and long-term health issues. ${ }^{8}$

Cancer may have multiple effects on quality of life of cancer patients. Cancer may induce socioeconomic difficulties, depression and social withdrawal in patients. Participation of cancer patients in self-care services induces behavioural improvements and improves wellness. Essentially, the best management strategy to this chronic illness is self-care, including patient involvement in self-monitoring, recognizing, identifying and reviewing symptoms and their severity, identifying and implementing treatment options, and assessing self-care results. ${ }^{9}$

Relevant information on self-care strategies should also be implemented at the start of chemotherapy with adequate supervision and input during the treatment process. ${ }^{10}$ Treatment of systemic cancer is consistent with a number of adverse effects that may adversely affect the quality of life of patients (QOL) and make it critical. Given that usually patients receive chemotherapy with ambulatory environments, symptoms at home need to be largely self-monitored. ${ }^{11}$

Cancer diagnosis may have a profound effect on mental health and wellbeing. Depression and anxiety can impair cancer treatment and rehabilitation, as well as quality of life and survival. ${ }^{12}$ Cancer patients' self-care therapeutic therapies have the potential to alleviate physical and psychosocial discomfort caused by cancer diagnosis and chemotherapy and to improve their quality of life. ${ }^{13}$ The need for education between these patients and their families is especially strong. Cancer care nurses are responsible for training patients before chemotherapy is given. ${ }^{14}$

The present study was conducted to assess the knowledge regarding self-care among patients receiving chemotherapy, to evaluate the effectiveness of information booklet regarding self-care among patients receiving chemotherapy and to find out the association between knowledge score regarding selfcare among patients receiving chemotherapy in selected hospitals.

\section{METHODS}

Quasi experimental one group pre-test post-test research design was used to conduct the study among cancer patients and a total of 60 cancer patients receiving chemotherapy were selected by non-probability convenience sampling technique. The sample size was calculated with prevalence of cancer patients. Approximately $39.5 \%$ of men and women will be diagnosed with cancer at some point during their lifetimes (based on 2015 - 2017 data). ${ }^{15}$

Data was collected by using structured questionnaire during the month of December 2019. Patients who are analphabetic, patients who are critically ill, patients who are unable to read booklet, patients those suffering from known mental disorders were excluded. A questionnaire was created in the most commonly spoken Marathi languages in that area. Participation was voluntary at the report and the participants answered the questionnaires themselves anonymously.

The content validity was determined after the opinion of experts in the field of medical-surgical, nursing and oncology nursing. Tool validation included measurement of interobserver reliability; the generation of criterion related, construct related and content related validity. The tool was later revised by English language expert and then translated into Marathi language by language expert without altering the tools meaning. The reliability of the tool was $r=0.80$. This is true and appropriate for patients receiving chemotherapy.

The Institutional Ethical Committee of the Datta Meghe, Institute of Medical Sciences, Deemed to Be University sanctioned approval for conducting the research study and was obtained. The findings were summarized by concentrations and percentages, category. The software used in the analysis were SPSS 24.0 and Graph Pad Prism 7.0 version and $\mathrm{P}<0.05$ is considered as level of significance.

The questionnaire consisted of parts for acquiring demographic information and relevant questions related to the knowledge about chemotherapy and self-care of the participants. After collecting the demographic data, the structured questionnaire regarding self-care during 
chemotherapy was provided and then information booklet regarding self-care was given to the patients. The post-test of the study was carried out on the seventh day after the provision of information booklet, using same questionnaire.

To accomplish the objective of the study, the investigator collected data from 60 patients by a self-prepared questionnaire including 35 questions based on various aspects of self-care that has to be taken during chemotherapy. Each correct answer carried 1 mark and 0 was given for the wrong response. Knowledge was graded from poor knowledge score to excellent knowledge score based on the obtained scores. Based on total number of correct responses, the degree of knowledge was classified as poor $(0-7)$, average $(8-14)$, good (15 - 21), very good (22 - 28) and excellent (29-35).

\section{Statistical Analysis}

Analysis of the data was done by using descriptive and inferential statistics both. Descriptive statistics was used to describe the basic features of the data in a study and the inferential statistics was used to make inferences from our data to more general conditions like the percentage-wise distribution of the patients receiving chemotherapy about their demographic characteristics was calculated. The statistical tests used for the analysis of the result were: Students paired t-test, student's unpaired t-test, one-way analysis of variance (ANOVA) and reliability analysis.

A suitable sample was drawn from the study population of 60 patients who were receiving chemotherapy in selected hospitals of Wardha and, Nagpur district. The data was collected to classify sample characteristics including age, gender, education, occupation, monthly income, area of residence, time period of cancer, and duration of chemotherapy.

\section{RESULTS}

\begin{tabular}{|c|c|c|c|}
\hline \multicolumn{2}{|c|}{ Demographic Variables } & $\begin{array}{l}\text { No. of } \\
\text { Patients. }\end{array}$ & $\begin{array}{c}\text { Percentage } \\
(\%)\end{array}$ \\
\hline \multirow{3}{*}{ Age in years } & 31 - 40 yrs. & 25 & 41.60 \\
\hline & 41 - 50 yrs. & 22 & 36.70 \\
\hline & $>50$ yrs. & 13 & 21.70 \\
\hline \multirow{3}{*}{ Gender } & Male & 22 & 36.70 \\
\hline & Female & 38 & 63.30 \\
\hline & Primary & 15 & 25.00 \\
\hline \multirow{3}{*}{ Education } & Secondary & 32 & 53.30 \\
\hline & Graduate & 12 & 20.00 \\
\hline & PG & 01 & 1.70 \\
\hline \multirow{6}{*}{ Occupation } & Labourers & 22 & 36.70 \\
\hline & Business & 16 & 26.60 \\
\hline & Pvt Service & 06 & 10.00 \\
\hline & Govt Service & 04 & 6.70 \\
\hline & Unemployed & 12 & 20.00 \\
\hline & $<5000 \mathrm{Rs}$ & 14 & 23.30 \\
\hline \multirow{3}{*}{$\begin{array}{l}\text { Monthly family income } \\
\text { (Rs) }\end{array}$} & $5001-10000 \mathrm{Rs}$ & 22 & 36.70 \\
\hline & $10001-20000 \mathrm{Rs}$ & 17 & 28.30 \\
\hline & $>20000 \mathrm{Rs}$ & 07 & 11.70 \\
\hline \multirow{3}{*}{ Area of residence } & Urban & 24 & 40.00 \\
\hline & Rural & 36 & 60.00 \\
\hline & $<1$ months & 09 & 15.00 \\
\hline \multirow{3}{*}{ Time period of cancer } & 2 - 5 months & 14 & 23.30 \\
\hline & $9-12$ months & 19 & 31.70 \\
\hline & $>12$ months & 18 & 30.00 \\
\hline \multirow{4}{*}{$\begin{array}{l}\text { Duration of } \\
\text { chemotherapy }\end{array}$} & $1-6$ months & 16 & 26.70 \\
\hline & 5 - 8 months & 07 & 11.60 \\
\hline & $9-12$ months & 18 & 30.00 \\
\hline & $>12$ months & 19 & 31.70 \\
\hline \multicolumn{4}{|c|}{$\begin{array}{l}\text { Table 1. Percentage Wise Distribution of Patients } \\
\text { According to Their Demographic Characteristics }\end{array}$} \\
\hline
\end{tabular}

Table 1 shows that $41.60 \%$ of the patients were in their age group of 31 - 40 year, $36.70 \%$ of them were in the age group 41 - 50 year and $21.70 \%$ of them were more than 50 years of age. The patients were educated up to primary standard are 25 $\%$, up to secondary are $53.3 \%$, up to graduation are $20 \%$ and only $1.70 \%$ of the patients were educated up to postgraduation, Percentage wise $36.70 \%$ of them patients were labourers, $26.60 \%$ of them were doing business, $10 \%$ of them were doing private services, $6.70 \%$ of them were doing government service and $20 \%$ of them were unemployed. $23.30 \%$ of the patients had family income of less than Rs. 5000 per month, $36.70 \%$ of them had monthly income of Rs. 5001 $10000,28.30 \%$ of them had monthly family income of 10001 - 20000 Rs and $11.70 \%$ of them had monthly income of more than Rs. 20000. The patients residing in urban area percentage wise is $40 \%$ and residing in rural area is $60 \%$. The percentage wise $15 \%$ of the patients had cancer from less than one month, $23.30 \%$ of them had from 2 - 5 months, $31.70 \%$ of them had cancer from 9 - 12 months and $30 \%$ of them had cancer from more than 12 months. $26.70 \%$ of the patients were taking chemotherapy from 1 - 6 months, $11.60 \%$ of them were taking from $5-8$ months, $30 \%$ of them were taking from $9-12$ months and $31.70 \%$ of the patients were taking chemotherapy from more than 12 month.

\begin{tabular}{|c|c|c|c|}
\hline \multirow{2}{*}{$\begin{array}{c}\text { Pre-Test } \\
\text { Knowledge }\end{array}$} & \multirow{2}{*}{ Score Range } & \multicolumn{2}{|c|}{ Pre-Test Knowledge Score } \\
\hline & & No of Patients & Percentage \\
\hline Poor & $1-7$ & 00 & \\
\hline Average & $8-14$ & 20 & 33.33 \\
\hline Good & $15-21$ & 37 & 61.67 \\
\hline Very good & $22-28$ & 03 & 5.00 \\
\hline Excellent & $29-35$ & 00 & 00 \\
\hline \multicolumn{2}{|c|}{ Minimum score } & \multicolumn{2}{|c|}{08} \\
\hline \multicolumn{2}{|c|}{ Maximum score } & \multicolumn{2}{|c|}{23} \\
\hline \multicolumn{2}{|c|}{ Mean knowledge score } & \multicolumn{2}{|c|}{$15.53 \pm 2.98$} \\
\hline \multicolumn{2}{|c|}{ Mean \% knowledge Score } & \multicolumn{2}{|c|}{$44.38 \pm 8.52$} \\
\hline \multicolumn{4}{|c|}{ Table 2. Assessment of Pre-Test Knowledge } \\
\hline $\mathrm{N}=60$ & & & \\
\hline
\end{tabular}

Table 2 indicates that $33.33 \%$ of patients had average knowledge scores, $61.67 \%$ had good knowledge scores, and 5 $\%$ had very good pre-test knowledge scores. Minimum score of knowledge was 8 in the pre-test and maximum score of knowledge was 23 in the pre-test. Mean knowledge score in pre-test was $15.53 \pm 2.98$ and mean percentage of knowledge score in pre-test was $44.38 \pm 8.52$.

\begin{tabular}{|c|c|c|c|}
\hline \multirow{2}{*}{$\begin{array}{l}\text { Post-Test } \\
\text { Knowledge }\end{array}$} & \multirow{2}{*}{ Score Range } & \multicolumn{2}{|c|}{ Post-Test Knowledge Score } \\
\hline & & No of Patients & Percentage \\
\hline Poor & $1-7(0-20 \%)$ & 00 & 0 \\
\hline Average & $8-14(21-40 \%)$ & 00 & 0 \\
\hline Good & $15-21(41-60 \%)$ & 07 & 11.67 \\
\hline Very good & $22-28(61-80 \%)$ & 49 & 81.67 \\
\hline Excellent & $29-35(81-100 \%)$ & 04 & 6.67 \\
\hline \multicolumn{2}{|c|}{ Minimum score } & \multicolumn{2}{|c|}{20} \\
\hline \multicolumn{2}{|c|}{ Maximum score } & \multicolumn{2}{|c|}{30} \\
\hline \multicolumn{2}{|c|}{ Mean knowledge score } & \multicolumn{2}{|c|}{$24.61 \pm 2.53$} \\
\hline \multicolumn{2}{|c|}{ Mean \% knowledge score } & \multicolumn{2}{|c|}{$70.33 \pm 7.25$} \\
\hline \multicolumn{4}{|c|}{ Table 3. Assessment of Post-Test Knowledge } \\
\hline 60 & & & \\
\hline
\end{tabular}

Table 3 shows that $11.67 \%$ of the patients had good knowledge score, $81.67 \%$ of them had very good knowledge score and $6.67 \%$ of them had excellent knowledge score in post-test. Minimum knowledge score was 20 in post-test and maximum knowledge score was 30 in the post-test. Mean percentage of knowledge score in post-test was $24.61 \pm 2.53$ and mean percentage of knowledge score in post-test was $70.33 \pm 7.25$. 


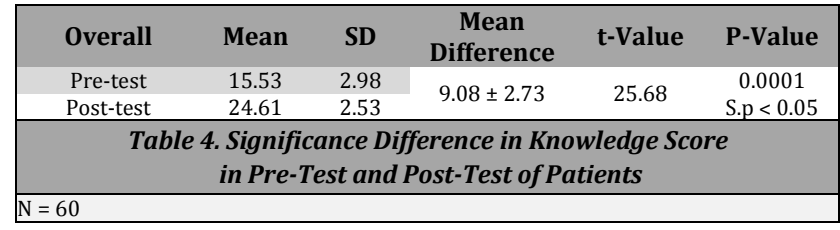

Table 4 indicate the comparison between pre-test and posttest information rates of patients on self-care. Mean, standard deviation and mean difference values are compared and 5 percent of significance is added to the student paired test. The tabulated value for $\mathrm{N}=60$ - 1, i.e. 59 degrees of freedom, was 2.00. The estimated value, i.e. 25.68 , is much higher than the tabulated value at 5 percent of significance for overall knowledge score of patients which is statistically acceptable of significance. Hence, it is statistically interpreted that the information booklet regarding self-care among patients receiving chemotherapy in selected hospitals was effective. Thus, the $\mathrm{H} 1$ is accepted.

\begin{tabular}{|c|c|c|c|c|c|}
\hline \multicolumn{2}{|c|}{ Demographic Variables } & No. of Patients & $\begin{array}{l}\text { Mean of Post-Test } \\
\text { Knowledge Score }\end{array}$ & F-Value & P-Value \\
\hline \multirow{3}{*}{ Age in years } & 31 - 40 yrs. & 25 & $23.84 \pm 2.30$ & \multirow{3}{*}{3.20} & \multirow{3}{*}{$\begin{array}{c}0.042 \\
\mathrm{~S}, \mathrm{P}<0.05\end{array}$} \\
\hline & 41 - 50 yrs. & 22 & $25.59 \pm 2.26$ & & \\
\hline & $>50$ yrs. & 13 & $24.46 \pm 3.01$ & & \\
\hline \multirow{3}{*}{ Gender } & Male & 22 & $23.72 \pm 2.64$ & \multirow{3}{*}{2.12} & 0.038 \\
\hline & Female & 38 & $25.13 \pm 2.36$ & & S, P $<0.05$ \\
\hline & Primary & 15 & $25.13 \pm 2.82$ & & \multirow{4}{*}{$\begin{array}{c}0.84 \\
\text { NS, } P>0.0\end{array}$} \\
\hline \multirow{3}{*}{ Education } & Secondary & 32 & $24.43 \pm 2.44$ & \multirow{2}{*}{0.27} & \\
\hline & Graduate & 12 & $24.50 \pm 2.64$ & & \\
\hline & PG & 01 & $24 \pm 0$ & & \\
\hline \multirow{6}{*}{ Occupation } & Labourer & 22 & $24.72 \pm 2.88$ & \multirow{6}{*}{0.96} & \multirow{6}{*}{$\begin{aligned} & 0.43 \\
\text { NS, } & P>0.05\end{aligned}$} \\
\hline & Business & 16 & $24.56 \pm 2.42$ & & \\
\hline & Pvt service & 06 & $25.66 \pm 2.58$ & & \\
\hline & Govt service & 04 & $22.50 \pm 1.29$ & & \\
\hline & Unemployed & 12 & $24.66 \pm 2.22$ & & \\
\hline & $<5000 \mathrm{Rs}$ & 14 & $24.28 \pm 2.52$ & & \\
\hline \multirow{3}{*}{ Monthly income } & 5001 - 10000 Rs & 22 & $25 \pm 2.81$ & \multirow{3}{*}{0.98} & \multirow{3}{*}{$\begin{aligned} & 0.40 \\
& N S, P>0.05\end{aligned}$} \\
\hline & $10001-20000$ Rs & 17 & $24.94 \pm 2.24$ & & \\
\hline & $>20000$ & 07 & $23.28 \pm 2.28$ & & \\
\hline \multirow{3}{*}{ Area of residence } & Urban & 24 & $24.75 \pm 2.19$ & \multirow{3}{*}{0.33} & \multirow{3}{*}{$\begin{array}{c}0.7 \\
\text { NS, } \mathrm{P}>0.05\end{array}$} \\
\hline & Rural & 36 & $24.52 \pm 2.77$ & & \\
\hline & $<1$ month & 09 & $23 \pm 1.87$ & & \\
\hline \multirow{4}{*}{ Time period of cancer } & $2-5$ months & 14 & $23.92 \pm 2.75$ & \multirow{2}{*}{2.89} & \multirow{3}{*}{$\begin{array}{c}0.043 \\
S, P<0.05\end{array}$} \\
\hline & $9-12$ months & 19 & $25.63 \pm 2.00$ & & \\
\hline & $>12$ months & 18 & $24.88 \pm 2.76$ & & \\
\hline & $1-6$ months & 16 & $23.18 \pm 2.34$ & \multirow{4}{*}{3.10} & \multirow{4}{*}{$\begin{array}{c}0.034 \\
\mathrm{~S}, \mathrm{P}<0.05\end{array}$} \\
\hline \multirow{3}{*}{ Duration of chemotherapy } & 5 - 8 months & 07 & $24.42 \pm 2.63$ & & \\
\hline & $9-12$ months & 18 & $25.66 \pm 2.05$ & & \\
\hline & $>12$ months & 19 & $24.89 \pm 2.68$ & & \\
\hline \multicolumn{6}{|c|}{$\begin{array}{c}\text { Table 5. Association of Post-Test Knowledge Score Regarding Self-Care among } \\
\text { Patients Receiving Chemotherapy in Relation to Demographic Variables }\end{array}$} \\
\hline
\end{tabular}

Table 5 shows that there was significant association of knowledge score in relation to age, gender, time period of cancer and duration of chemotherapy. Education, occupation, monthly family income and area of residence were not significantly associated with knowledge score.

\section{DISCUSSION}

The present study focuses on to evaluate the effectiveness of information booklet regarding self-care among patient receiving chemotherapy at Rashtra Sant Tukdoji Regional Hospital Nagpur and Acharya Vinoba Bhave Rural Hospital Sawangi, Meghe, Wardha, Maharashtra. The findings of the present study were discussed with reference to the objectives and with the findings of the other studies.

Manisha C. Gholap, 2019, a study to evaluate the effectiveness of information booklet regarding self-care during chemotherapy among cancer patients at selected tertiary care hospital, Karad. One group pre-test post-test experimental design used by researcher to conduct study among patients diagnosed with cancer and by using convenience sampling technique, 38 cancer patients were selected. With the help of structured questionnaire, data was collected. The finding of the study reveals that age and gender were not significantly associated with self-care during chemotherapy and the education was found to be significantly associated with self-care during chemotherapy ${ }^{6}$

Haryani Haryani, 2017, Implementation of self-care symptom management program to enhance the quality of life of cancer patients undergoing chemotherapy and their family caregivers. The researcher used one group pre-intervention and post-interventional test, with quasi-experimental design. The research was conducted with 40 cancer patients and 30 family caregivers in a public hospital in Yogyakarta, Indonesia. The results of the study indicate that there were no significant differences between the pre-intervention score and the postintervention score. The findings of this randomized study corroborate previous evidence that the provision of wellstructured and adequate written information on cancer care is highly appreciated and beneficial to patients.

\section{CONCLUSIONS}

Information related to chemotherapy self-care includes various aspects like knowledge regarding purpose of self-care, pain management, managing nausea and vomiting, hair and skin care, managing stress and fatigue and nutrition. Knowledge of selected patients regarding self-care was inadequate; providing information booklet helped the patients to understand more about chemotherapy self-care. Thus, 
information booklet is effective in improving knowledge of patients regarding self-care during chemotherapy.

Data sharing statement provided by the authors is available with the full text of this article at jemds.com.

Financial or other competing interests: None.

Disclosure forms provided by the authors are available with the full text of this article at jemds.com.

\section{REFERENCES}

[1] Nies YH, Ali AM, Abdullah N, et al. A qualitative study among breast cancer patients on chemotherapy: experiences and side-effects. Patient Prefer Adherence 2018;12:1955-64.

[2] Saraswat N, Chopra A, Sood A, et al. A descriptive study to analyse chemotherapy-induced hair loss and its psychosocial impact in adults: our experience from a tertiary care hospital. Indian Dermatol Online 2019;10(4):426-30.

[3] Sarita D, Preksha S, Shaminder K. Knowledge and attitude regarding safe handling of chemo among nurses: a cross sectional survey. International Journal of Curr Research 2019;11(8):6380-6.

[4] Guswiler KA. Cancer patients' response to chemotherapy teaching on side effect management. Masters Theses 115. Grand Valley State University. Graduate Research and Creative Practice 1991. https://scholarworks.gvsu.edu/theses/115

[5] Mohsen MM, Fareed ME. Chemotherapy safety protocol for oncology nurses: it's effect on their protective measures practices. International Journal of Medical and Health Sciences 2013;7(9):529-37.

[6] Gholap MC, Choudhari SK, Mohite VR. A study to evaluate the effectiveness of information booklet regarding self- care during chemotherapy among cancer patients at selected tertiary care hospital, Karad. International Journal of Health Sciences and Research 2019;9(7):69-72.

[7] Mehta RS. Jaypee Oncology nursing. $1^{\text {st }}$ edn. New Delhi: Jaypee Brothers Medical Publishers 2008.

[8] Foster C, Fenlon D. Recovery and self-management support following primary cancer treatment. Br J Cancer 2011;105(Suppl 1):S21-8.

[9] Hasanpour-Dehkordi A. Self-care concept analysis in cancer patients: an evolutionary concept analysis. Indian J Palliat Care 2016;22(4):388-94.

[10] Maikeow K. Self-care behaviours of chemotherapy patients. J Med Assoc Thai 2012;95(Suppl 6):30-7.

[11] Warrington L, Absolom K, Holch P, et al. Online tool formonitoring adverse events in patients with cancer during treatment (eRAPID): field testing in a clinical setting. BMJ Open 2019;9(1):e025185.

[12] Niedzwiedz CL, Knifton L, Robb KA, et al. Depression and anxiety among people living with and beyond cancer: a growing clinical and research priority. BMC Cancer 2019;19(1):943.

[13] Richardson A. Studies exploring self-care for the person coping with cancer treatment: areview. Int J Nurs Stud 1992;29(2):191-204

[14] Elshamy K. Effect of implementing a prechemotherapy education programme on psychological distress, quality of life and satisfaction of Egiptian women newly diagnosed with breast cancer. Arch Can Res 2016;4:2.

[15] Haryani H, Rachmat K, Suseno P, et al. Implementation of self-care symptommanagement program to enhance the quality of life of cancer patients undergoing chemotherapyand their family caregivers. Int J Res Med Sci 2017;5(6):2442. 